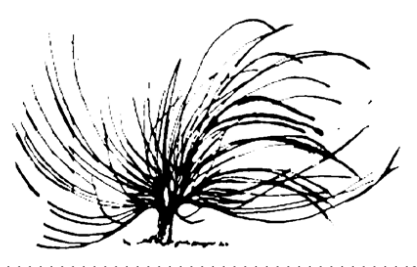

\title{
A escrita sobre as práticas dos professores em formação. $O$ relatório enquanto mediatário na educação acadêmica
}

\author{
Rogério Pereira Costa \\ Universidade Federal do Pará \\ Brasil \\ rogerio.pereira.costa@hotmail.com
}

\begin{abstract}
Resumo
O objetivo deste artigo é discutir como os saberes são constituídos e descritos nas disciplinas de estágio supervisionado e, para isso, identificaremos, com base em relatórios de estágio de graduandos em Letras de diferentes universidades, duas questões fundamentais sobre o processo da produção e recepção de conhecimento por meio da escrita, as quais são: i) como se dá a descrição de vozes nos relatórios de estágio; ii) como ocorre a manipulação do tempo nos relatórios. Com base na análise linguística dos produtos escritos dos graduandos, a discussão realizada aqui esclarece elementos fundamentais em torno de como se dá o construto teórico dos professores em formação, visto que a disciplina de estágio supervisionado necessita de um olhar mais rigoroso. A escrita do estagiário fornece elementos fundamentais sobre a sua produção de conhecimento, mostrando que o gênero relatório de estágio reflete um formato genérico e com superficialidade teórica.
\end{abstract}

\section{(c) $(1) \Theta \theta$}

http://dx.doi.org/10.15359/rep.esp-20-1.10

1 Graduando em Letras - Língua Portuguesa pela Universidade Federal do Pará; bolsista do Programa Institucional de Bolsas de Iniciação à Pesquisa (PIBIC/UFPA) vinculado ao projeto "A escrita sobre as práticas de ensino em licenciaturas do Brasil, da Costa Rica e de Honduras: registro, análise e produção de conhecimento" (CNPq 458449/2014-8). 
Palavras-chave: relatórios de estágio; formação de professores; vozes; tempo.

\begin{abstract}
The purpose of this paper is to analyze how knowledge is constructed and how it is described in the courses of supervised professional practicum. To achieve this, based on undergraduate students' practicum reports from various universities, we identified two fundamental questions in the process producing and receiving knowledge by means of writing, which were i) what is the description of the voices in the practicum reports like? and ii) how does time management happen in the reports? Based on the linguistic analysis of the students' written products, the emphasis is on the theoretical construction of the preservice teachers since the supervised practicum requires a more rigorous look. Practicing students' writing provides key elements in the production of knowledge, showing that the genre of practicum reports reflects a general format and theoretical superficiality.
\end{abstract}

Keywords: practicum reports, teacher education, voices, time

\title{
Introdução
}

$\mathrm{N}$

este texto discutiremos os resultados do plano de pesquisa PIBIC/UFPA desenvolvido em 2014-2015 e inserido, por sua vez, no projeto $A$ escrita sobre as práticas em licenciaturas do Brasil, da Costa Rica de Honduras: registro, análise e produção de conhecimento2. O referido plano de trabalho tem como corpus de pesquisa relatórios de estágio supervisionado de graduandos em Letras da Universidade Federal do Pará, considerando que o estágio não deve apenas consistir na documentação das atividades observadas durante o estágio supervisionado, mas deve contribuir também para a produção de conhecimento.

A pesquisa teve início a partir da necessidade de explicar como os estagiários registram as falas dos professores e alunos, além de observar como ocorre a transcrição dos conteúdos do quadro ou do

2 Chamada universal MCTI/CNPQ No 14/2014, coordenado pelo professor Thomas Fairchild. 
material didático para os relatórios de estágio. Pretendemos observar como dados se articulam para prestar conta da atividade comprobatória de estágio supervisionado e, além disso, produzir conhecimento sobre a aula.

Perguntamos se, durante o estágio supervisionado, os graduandos em Letras sabem favorecer o encontro entre os saberes docentes adquiridos durante a graduação e o registro feito a respeito das aulas. Com base nos relatórios trataremos de questões no campo do discurso citado e sobre a construção discursiva e a articulação do tempo nos relatórios. Para isso, dividimos o texto nas seguintes partes: "1. O discurso relatado na enunciação: dos verbos dicendi às expressões que indicam os atos das falas"; e "2. A construção temporal nos relatórios de estágio".

Na primeira parte, discutiremos questões que dizem respeito aos verbos dicendi $i^{3}$, visto que esses verbos funcionam como indicadores dos atos de fala e, também, funcionam como verbos declarandi, carregando consigo um juízo de valor que expressa uma relação comunicativa entre sujeitos. Por outro lado, os indícios de vozes ocorrem, também, por meio de expressões que indicam os atos de fala, expressões essas que surgem como indicadores dos atos de locução no discurso relatado e, para isso, as expressões funcionam apenas como indicadores, mas que subtraem os discursos que deveriam ser expressos pelo relato do estagiário.

Para apontarmos as questões discutidas dentro do presente trabalho, utilizamos um quadro teórico sob a perspectiva da análise do discurso de Maingueneau (1989) e José Luiz Fiorin (1996), entre outros autores relevantes para apontarmos as questões aqui discutidas.

Os resultados nos levam a discutir a produção de conhecimento dos professores em formação, considerando que produção de conhecimento é, segundo nossos postulados, a consolidação do desenvolvimento de análise e reflexão dentro da sua área de atuação, este que, por vezes, é revelado por meio da escrita, momento esse em que vemos a somatória de teorias e práticas desenvolvidas dentro da escrita. Os resultados mostram que nos relatórios de estágio pode ocorrer um apagamento de informações fundamentais para que possamos compreender o desenvolvimento da aula, logo é identificável que ocorrem

3 Há uma grande variedade lexical em relação aos verbos, de modo que os verbos dicendi apresentem indícios de que há uma enunciação encaixada na outra, na qual o verbo introduz um quadro interior que está dentro do discurso citado, seja ele direto ou indireto. Havemos de apontar que os verbos dicendi funcionam como indicadores do discurso relatado. 
descrições genéricas, o que prejudica o confronto dos saberes teóricos e a observação metodológica das aulas. Com vistas a apresentar uma proposta de análise discursiva dos relatórios de estágio, identificaremos alguns apontamentos sobre a complexidade dos produtos escritos e as análises que chegamos ao final do processo, como veremos a seguir.

\section{O discurso relatado na enunciação: dos verbos dicendi às ex- pressões que nomeiam os atos de fala}

A finalidade da análise apresentada neste item é observar as diferentes formas de relatar a enunciação ${ }^{4}$ na escrita de relatórios de estágio. $\mathrm{Na}$ citação do discurso do outro, identificamos que ocorre, frequentemente, a omissão de vozes durante a descrição das aulas, vozes essas que são fundamentais para termos a aula enquanto dado concreto sobre o material observado. Além disso, compreendemos que o estagiário, ao assumir "autoridade" perante o discurso, invoca certa autoridade em função daquilo que está sendo dito; logo percebemos que, em alguns momentos, o relato do estagiário é insuficiente para sua formação, pois há um apagamento de discursos e supressão de informações necessárias para se poder expandir a reflexão sobre as situações de ensino relatadas.

Os verbos dicendi são verbos de elocução presentes em um texto oral ou escrito, que expressam a forma como a pessoa do discurso se apresenta. Eles colocam à disposição marcas semânticas que são vistas como verbos ou expressões, portanto a semântica desses verbos pode contestar, responder, exclamar ou até mesmo pedir.

Centrando nossa investigação nos verbos dicendi, afirmamos que eles são considerados a variação da locução; desse modo, esses verbos são dicendi ou verbos de sentir, segundo Rodrigues (2000), e possuem a mesma classificação, pois determinam certa afetividade no texto ao deixar evidências do sujeito de consciência dentro do enunciado. Se observarmos dentro de uma literatura de ficção, por exemplo, podem ser identificados esses verbos de modo que o narrador da história pode escolher o uso do discurso direto, indireto ou indireto livre, e no momento em que o narrador recorre à utilização do verbo para que sejam indicados atos de fala, este caracteriza-se como verbo dicendi, ou de dizer.

4 De acordo com Maingueneau "é designado ao produto da enunciação, do ponto de vista sintático considera-se a frase como um tipo de enunciado, equivalendo por consequência o mesmo que um texto" (1989, p. 54). 
Expandindo nossa explicação em torno dos verbos dicendi, havemos de afirmar que eles apontam os diálogos que serão postos seguidos do verbo, de modo que o interlocutor ${ }^{5}$ do enunciado está com a palavra, descrevendo, portanto um discurso reportado de outro sujeito. Ilustraremos isso com um exemplo baseado no texto literário Auto da Compadecida $^{6}$, de Ariano Suassuna ${ }^{7}$. João Grilo, ao conversar com o Padre pedindo para que ele possa benzer o cachorro do major, responde da seguinte forma após ser questionado pelo Padre: "- Eu disse que uma coisa era o motor e outra o cachorro do major Antônio Morais" (Suassuna, 1998, p. 6). Essa frase escrita por meio do discurso direto mostra que João Grilo está com a palavra, retomando algumas afirmações ditas por ele anteriormente. Com base nesse trecho, vemos que o personagem João Grilo toma para si os fenômenos íntimos do enunciado, e que poderia também abrir, por meio do diálogo, espaço para suas emoções, seguido de verbos, de modo que o verbo disse indica um diálogo reportado por ele.

Dentro dos relatórios de estágio é muito comum identificar o uso dos verbos dicendi, pois o aluno, ao relatar a aula, acaba exprimindo sua voz e opinião a respeito da observação; além disso, o estagiário promove a fala do professor e aluno inserindo verbos para sua construção enquanto locutores, o que, por vezes, surge de forma generalizada ou até mesmo omissa, pontos esses que serão tidos em conta, no decorrer da exposição.

Para compreendermos o funcionamento do discurso, apontamos que tanto o discurso oral quanto o escrito podem variar entre discursos direto, indireto e indireto livre. Esses tipos de discursos, segundo Maingueneau, tratam-se das "manifestações mais clássicas da heterogeneidade enunciativa" (1989, p. 85). Partimos do princípio de que o estagiário pode proferir dentro do seu produto escrito os discursos que são incorporados por ele.

$5 \quad{ }^{3}$ Manifestação do sujeito falante (orador/narrador) dentro de um discurso oralizado ou escrito, de forma que toma como objeto a sua própria mensagem.

6 Escrito em 1955, é considerado um clássico da Literatura brasileira, possui uma medalha de ouro da Associação Brasileira de Críticos Teatrais. Além disso, é uma peça teatral em forma de auto, sendo ela dividida em três atos, os quais exibem os elementos da Literatura de Cordel ao apresentar traços do barroco católico do nordeste brasileiro.

7 Poeta e romancista brasileiro, nascido na Paraíba, procurava em suas manifestações literárias favorecer a cultura do nordeste brasileiro, tendo como cânone literário as obras: Auto da Compadecida e D'a pedra do reino. 
Dando ênfase aos discursos identificados nos relatórios, apontamos que no discurso direto, por exemplo, os personagens ganham voz; ele geralmente ocorre em conversas, destacando consequentemente a fala e as características dos "personagens" presentes dentro do discurso. No discurso indireto, por sua vez, o narrador constrói os fatos e, por meio da terceira pessoa, utiliza suas próprias palavras para reproduzir as vozes dos personagens. No discurso indireto livre, afirma-se, segundo Maingueneau, que "está ligado à propriedade notável que possui de relatar alocuções fazendo ouvir duas vozes diferentes inextricavelmente misturadas" (1989, p. 97). Logo, nesse tipo de discurso, há certa discordância em torno do indivíduo que relata as alocuções, essas que nada mais são que as outras vozes relatadas pelo enunciador e que estão em torno do indivíduo que relata as locuções, como também os indivíduos que têm suas vozes descritas.

Vale ressaltar que, dentro dos relatórios que analisamos, há uma prevalência do discurso indireto, pois o estagiário ao narrar os fatos ocorridos em sala de aula acaba reproduzindo as locuções citadas no momento do acontecimento. Segundo Maingueneau (1989) as locuções citadas, no discurso indireto, poderiam ser vistas como uma espécie de "teatralização de uma enunciação anterior e não uma similitude absoluta" (1989, p. 85). Logo as locuções citadas apresentam uma relação de semelhança entre o modelo real e o resultado imitado na hora da enunciação, de modo que os diálogos passam a ser formulados a partir do interesse de quem enuncia, e a voz não passa mais a pertencer ao locutor de origem e sim a quem produz o texto teatralizando os diálogos identificados no momento de observação.

O estagiário representa, por meio de suas palavras, os diferentes enunciadores, esses sujeitos que têm suas vozes representadas por um único enunciador, que, de certa forma, atribui palavras categóricas para representá-los. Com base nisso, o enunciador cria uma cena enunciativa para que possa representar os diferentes sujeitos presentes no momento de observação, logo o estagiário enunciador se responsabiliza por sua enunciação e as diferentes locuções presentes no enunciado. Por outro lado, a percepção que o enunciador estagiário tem dessa "cena" e o modo como ele a constrói em seu discurso estão sujeitos aos efeitos das formações discursivas dentro das quais ele produz seu enunciado (o relatório). 
A partir do momento que se trata de formações discursivas, toda concepção retórica da citação é inadequada. O sujeito que enuncia a partir de um lugar definido não cita quem deseja, como deseja, em função de seus objetivos conscientes, do público visado etc. São as imposições ligadas a este lugar discursivo que regulam a citação. Esta noção de citação é, entretanto, ambígua, pois remete tanto às regras, às concepções, quanto aos enunciados citados. (MAINGUENEAU, 1989, p. 86)

Um enunciador, ao produzir os discursos visando o público leitor previamente definido, pode manipular os seus dados de escrita para que possa convencer quem estará lendo o seu relatório. Portanto, o público é que define as citações de fala, embora o sujeito possua autoridade sobre o próprio discurso. Para tanto havemos de afirmar que, no momento da descrição de uma aula, o estagiário A, por exemplo, possui um grupo de interlocutores situado numa situação $X$ e em um determinado tempo e lugar; para isso o estagiário visando o grupo previamente definido manipula os dados de aula.

Consideramos que nos diferentes tipos de diálogos identificados em um discurso relatado, nos relatórios de estágio, ocorre certa inadequação, afinal quando identificamos um discurso relatado vemos que há certo distanciamento entre as vozes identificadas em sala de aula e as vozes descritas nos relatórios, perdendo, portanto, a similitude.

Ao trazermos essas afirmações ao campo do relatório de estágio, apontamos que o estagiário, quando produz um enunciado, acaba consequentemente manobrando as diferentes locuções observadas em sala de aula, embora ele esteja sujeito à formação discursiva, logo seja pelo discurso direto, indireto ou até mesmo pelo indireto livre os discursos relatados sempre sofrerão certo distanciamento se comparados com as falas ocorridas no momento do acontecimento.

Ilustraremos estas discussões com base em alguns excertos extraídos dos relatórios de estágio que compõem a pesquisa.

(i) A professora entrou na sala, fez a chamada e disse aos alunos que passaria uma revisão sobre o tema "sujeito" antes de entregar o exercício "extra”. Pediu para que eles prestassem bastante atenção para que pudesse recuperar a nota da prova. Os alunos comemoraram a revisão e pareceram interessados na explicação. 
A maior parte da sala ficou concentrada e em silêncio enquanto a professora escrevia na lousa.

(ii) A professora explicou o conteúdo que estava no quadro, interagindo com os alunos durante os exemplos, pedindo para que eles identificassem o sujeito das orações transcritas sempre após as explicações. Os alunos conseguiram responder corretamente todas as perguntas, cerca de seis ou sete alunos estavam respondendo, porém, observei os cadernos e todos estavam acompanhando a leitura e marcando os sujeitos, mesmo sem responder em voz alta.

Podemos dizer que o estagiário manipula as diferentes vozes presentes na aula, de modo que ele "escuta" uma parte das vozes que compõem a aula, e ao passar para o relatório escrito identificamos que ocorre uma segunda supressão de informações, como no modo que o estagiário utiliza as palavras para reproduzir aquilo que foi dito. Como afirma Fiorin, "o discurso indireto depende do momento da enunciação do narrador e não mais do momento da fala do interlocutor" (1996, p. 179). Vemos que as locuções presentes na aula acabam sendo esquecidas ou parcialmente modeladas de acordo com as marcas do discurso do próprio narrador. Em alguns excertos podemos analisar esses tipos de ocorrências, como nos casos acima.

No excerto (i), por exemplo, percebemos que o uso dos verbos disse e pediu anunciam o ato de locução do professor no discurso indireto (marcado em itálico), no entanto não conseguimos observar de forma clara os argumentos utilizados pela professora, elementos esses fundamentais que deveriam aparecer para prestar conta dos fatos ocorridos em determinado tempo de aula. Esse excerto nos faz afirmar que, embora o discurso da professora apareça suprimido, ainda conseguimos identificar implicitamente os atos de locução por meio do discurso indireto, pois há um breve esclarecimento de que a professora afirmou que passaria uma revisão; além disso, conseguimos também identificar o que a professora havia pedido aos alunos. Logo, o presente dado nos faz observar que embora ocorra certa supressão de informações ainda conseguimos identificar parte dos diálogos da professora, no entanto vale destacar que a supressão de informações é vista como algo negativo, pois o leitor não consegue obter informações claras a respeito de como se deu a fala da professora. 
No excerto (ii) ocorre algo semelhante, no entanto, vemos que os atos de locuções não aparecem por meio do discurso indireto (com exceção do verbo pedindo, que por meio do discurso indireto mostra, em parte, que a professora pediu para que eles identificassem o sujeito das orações.). O que identificamos é que ocorre o aparecimento de expressões que nomeiam os atos das falas, no entanto, sem registrar o conteúdo do discurso citado (diferentemente do que ocorre com verbos dicendi). O problema que identificamos, portanto, é que não conseguimos observar as vozes ali presentes, seja pelo discurso indireto ou direto, pois as vozes ali aparecem apenas por indícios oferecidos pelas expressões nomeadoras como nos casos de conseguiram responder $\mathrm{e}$ estavam respondendo.

Outro fenômeno observado é que não conseguimos identificar a forma como a professora realizou a interação com os alunos, porém, em seguida, a estagiária afirma que a professora pediu para que fossem identificados os sujeitos das orações, logo inferimos que a interação foi realizada no momento em que foi pedida a identificação dos sujeitos. Embora possamos reconhecer que foi realizada a interação entre os alunos, não temos subsídios concretos para observarmos a forma como foi realizada essa interação.

Os dois fenômenos identificados nos exemplos acima nos fazem perceber que o discurso relatado é heterogêneo, pois os relatórios oscilam entre o discurso direto, indireto e indireto livre, e de alguma maneira classificam as marcas da heterogeneidade discursiva. Além desses dados conseguimos realizar outros apontamentos referentes ao mesmo tipo de problema, como veremos a seguir.

(iii) A professora corrigiu no quadro as questões, assim os alunos que não levaram o caderno para ela corrigir, resolveram. A professora despediu-se dos alunos e disse que na próxima aula conversariam mais sobre as palavras oxitonas, paroxitonas e proparoxitonas e pediu para que eles pesquisassem em livros, revistas, jornais, mais exemplos dessas palavras.

(iv) Então a professora fez uma breve revisão para eles e muitos lembraram, dava para perceber isso, porque eles diziam " $a h$, siiiimmm, agora entendi!". 
Nesses dois excertos conseguimos apontar que ocorrem, de forma geral, supressão de informações. No excerto (iii) vemos que há utilização de expressões que nomeiam o ato da fala nos casos de corrigiu, resolveram e despediu-se. Nesses casos não conseguimos identificar o conteúdo dos atos de fala, afinal não percebemos como a professora despediu-se dos alunos e, principalmente, como a professora realizou a correção no quadro. Em contrapartida, conseguimos identificar verbos dicendi que dão indícios por meio do discurso indireto os atos de fala, como podemos identificar nas passagens disse e pediu. Embora possamos ter indícios de como ocorreu a aula, não temos, principalmente, a forma como a professora corrigiu as questões e a forma como os alunos responderam, e esses dois pontos são fundamentais para que o estagiário se posicione ante o conteúdo ministrado.

No excerto (iv) é identificável que ocorre novamente um apagamento de informações fundamentais, pois não conseguimos identificar como a professora fez uma breve revisão, portanto não são visíveis os acontecimentos descritos dentro dessa revisão. Posto isso, vemos claramente que ocorreu a utilização de uma expressão que dá indício de um ato de fala, mas ocorre o apagamento do conteúdo do discurso citado dentro desse enunciado.

Ainda no excerto (iv) conseguimos identificar o discurso direto, como indicado em itálico; nesse momento é visível que a estagiária, ao relatar a locução, indica por meio do trecho entre aspas a locução dos alunos, e essa sequência de discurso é integrada ao enunciado, de modo que o locutor assumiu para si as diferentes vozes presentes em sala de aula e, de modo suprimido, demarcou de forma generalizada a resposta que representasse a maior parte da turma; não sabemos certamente se todos os alunos tiveram a mesma reação ao assumir que entenderam a atividade. Essa demarcação discursiva entre aspas indica o seu exterior, aquilo que está longe do enunciador, logo um discurso entre aspas deixa-nos perceber que nada do discurso foi assumido. Para J. Authier (apud Maingueneau, 1989), "atribuir várias funções a esta operação de distanciamento: aspas de diferenciação, destinadas a mostrar que nos colocamos além destes enunciados, irredutíveis às palavras empregadas".

Com base nos excertos analisados anteriormente, apontamos que os verbos dicendi apresentam os atos de fala por meio do discurso indireto ou direto. Embora os atos de locução apareçam suprimidos 
ou parcialmente ditos conseguimos identificar, em parte, as locuções ali presentes. O seu uso nos relatórios é importante porque pretende mostrar que há uma enunciação encaixada na outra, retomando os acontecimentos e diálogos, de modo que fornece ao leitor um quadro interior para que possamos interpretar o que está além do discurso; além disso, as operações interpretadas nos fazem refletir ao papel do narrador estagiário e o resultado a que ele chega ao final do processo.

Por outro lado, identificamos expressões que nomeiam os atos das falas, essas que indicam os atos de locução. No entanto, embora os estagiários indiquem por meio das expressões que há indícios de locução, não conseguimos identificar o conteúdo das falas ali presentes em nenhum dos tipos de discurso. Com base nessas afirmações elaboramos um quadro que representa a distinção entre os verbos dicendi e as expressões que nomeiam os atos de fala:

\begin{tabular}{|l|l|}
\hline VERBOS DICENDI & $\begin{array}{l}\text { EXPRESSÕES QUE INDICAM } \\
\text { OS ATOS DA FALA }\end{array}$ \\
\hline Disse & Explicou \\
\hline Pedindo & Interagindo \\
\hline Pediu & Conseguiram responder \\
\hline Disse & Estavam respondendo \\
\hline Pediu & Corrigiu \\
\hline Diziam & Despediu-se \\
\hline & Fez uma breve revisão \\
\hline
\end{tabular}

Vale ressaltar, de acordo com a distinção levantada entre os verbos dicendi e as expressões que indicam os atos de fala, que os estagiários as utilizam intencionalmente, afinal há uma lógica entre os diferentes empregos. Com base nisso vemos, de acordo com o quadro, que as expressões que indicam os atos de fala carregam consigo uma maior responsabilidade por designar os conteúdos substanciais importantes quando nos referimos ao que foi ministrado e discutido durante o estágio supervisionado, enquanto os verbos dicendi aparecem onde há discussões menos importantes e que não se referem aos conteúdos ministrados pelos professores.

Posto isso, validamos o quadro ao identificar que no uso das expressões ocorre o desaparecimento de informações em torno do conteúdo das aulas como, por exemplo, a forma como a professora explicou 
ou até mesmo como os alunos responderam. Essas informações suprimidas poderiam funcionar como dados comprobatórios da atividade de estágio supervisionado, como também funcionariam como dado de observação para que o estagiário se posicionasse por meio da palavra ante aquilo que por ele está sendo descrito.

Trazendo essas afirmações aos excertos extraídos dos relatórios de estágio, podemos claramente notar a distinção entre verbos dicendi e expressões que indicam o ato da fala, pois no primeiro conseguimos identificar os atos de fala por meio do discurso direto e indireto, mesmo que ainda haja supressão de informações, no entanto, quando identificamos as expressões vemos que o apagamento de informações é maior - o que vemos são apenas indícios genéricos de fala e que não chega a ser um conteúdo substancial válido.

Nos dados extraídos e classificados na tabela, observamos horizontalmente, na primeira linha, que na utilização do verbo disse, retirado do excerto (i), mostra o ato de locução da professora por meio do discurso indireto: "A professores entrou na sala, fez a chamada e disse aos alunos que passaria uma revisão sobre o tema "sujeito" antes de entregar o exercício "extra",". Nesse caso, como já mencionado, identificamos o ato de locução indiretamente; além disso, podemos construir a cenografia do enunciado, pois é observável dentro da oração o diálogo da professora. Enquanto isso, sobre o caso de explicou, retirado do excerto (ii): "A professora explicou o conteúdo que estava no quadro, interagindo com os alunos durante os exemplos", observamos que a estagiária menciona que a professora explicou o conteúdo que estava no quadro, no entanto não identificamos a forma como a professora realizou a explicação e tampouco os exemplos utilizados e a passagem do tempo dentro da sua explicação, embora saibamos posteriormente que houve interação com os alunos.

A partir do traço verbal buscamos um diálogo como compreensão do fato descrito, o que poderíamos chamar de pequenos fatos verdadeiros, os quais são fundamentais para representar e apreender o enunciado. Ante disso, precisamos observar nas expressões que indicam o ato da fala o que se diz depois do verbo, caso contrário o episódio narrado estará suprimido no enunciado e apenas a intuição do leitor virá suprir essa lacuna deixada pela expressão indicadora da fala. 


\section{A construção temporal nos relatórios de estágio}

Com base na análise discursiva da linguagem reconhecemos que dentro dos relatórios de estágio ocorre frequentemente um apagamento de informações fundamentais para compreendermos o desenvolvimento da aula e os acontecimentos ali presentes. Além disso, podemos perceber que as vozes dos sujeitos presentes dentro da sala de aula acabam muitas vezes suprimidas ou parcialmente ditas. A partir dessas questões iremos analisar, sob o olhar discursivo da linguagem, a escrita do estagiário enquanto produtor de conhecimento, analisando do ponto de vista enuncivo e enunciativo (Fiorin, 1996) o posicionamento do estagiário, por meio da escrita, no que diz respeito à construção de referências de temporalidade.

Deve-se considerar que o uso do tempo nas produções textuais, como os relatórios, reflete na produção escrita em que os saberes dos acontecimentos descritos estão ocorrendo, logo a prestação de contas do tempo é fundamental para que possamos conhecer: a) se o estagiário de fato cumpriu a carga horária indicada no relatório; b) como o tempo foi usado nas aulas observadas ou ministradas; c) como o estagiário percebe e se posiciona sobre o uso do tempo.

Para compreendermos o cenário no qual o estagiário está inserido, recorremos à escrita para tomarmos conhecimento dos fatos ocorridos em sala de aula. Para isso reconhecemos o estagiário enquanto sujeito que constrói um ponto de vista em sala de aula; a partir dessa perspectiva, o relatório de estágio funciona como algo mais que um texto comprobatório da atividade disciplinar de estágio supervisionado, contendo também argumentos fundamentais para afirmar se de fato houve produção de conhecimento. Vemos que o estagiário, ao produzir o relatório, determina para si e para o leitor várias vozes; por outro lado, vemos que os acontecimentos da aula acabam sendo omitidos, caracterizando-se como descrições genéricas e com poucos dados.

Para compreendermos os pressupostos da nossa teoria, afirmamos com base em Benveniste (apud Fiorin, 1996) que o tempo linguístico é irredutível, seja ao tempo crônico, seja ao tempo físico. Portanto, para o autor, há um tempo específico da língua. Essas afirmações nos fazem declarar que o tempo linguístico carrega características peculiares para prestar conta dos fatos ocorridos em diferentes momentos. Dessa forma, 
compreender o tempo é compreender as próprias estruturas linguísticas atrás de uma fonte que nos leve ao momento de anunciação.

Como afirma José Luiz Fiorin (1996, p. 142), "o discurso instaura um agora da enunciação, e esse agora é o fundamento das oposições temporais da língua". Há de se afirmar que o enunciado do estagiário é reinventado a cada vez que ele enuncia. Vemos que o uso dos discursos nos relatórios dá vida a essa afirmação, além de considerarmos que a descrição dos acontecimentos nos relatórios tenta nos aproximar do momento do acontecimento.

As premissas que sustentam nossas reflexões nos levam a observar que os verbos servem para constituir a temporalidade nos enunciados. Além disso, podemos identificar que os estagiários utilizam elementos temporais que dão indícios dos fatos dentro da uma sequência descritiva que, no entanto, muitas vezes se mostram genéricos e que não determinam os acontecimentos sobre o material observado, como veremos a seguir:

(v) Mesmo o professor ressaltando que valia ponto para a prova, as conversas paralelas continuaram. Depois de algum tempo, o educador deu início à explicação sobre o exercício e, logo após o término da correção, explanou sobre os casos especiais em que ocorre a acentuação gráfica. Ao final deste momento, o professor pediu para que os alunos abrissem o livro e vissem, no sumário, a parte que explicava algumas questões para a atividade. Feito isso, o docente saiu da sala, por alguns minutos, e depois retornou fazendo a chamada e encerrando a aula.

Os elementos em negrito sublinhados, de alguma forma, servem para relatar aspectos temporais dos acontecimentos observados durante a aula. Na passagem depois de algum tempo, por exemplo, não vemos evidencias claras sobre os fatos presentes durante esse período, pois não temos indícios dos fatos ocorridos ao longo desse tempo indeterminado. $\mathrm{O}$ mesmo se passa com a expressão ao final deste momento. Em relação à construção do tempo há de se afirmar que houve uma prestação de contas genérica dos fatos observados em sala de aula.

Convêm destacarmos também que os relatórios de estágio utilizam a mudança no aspecto do verbo para tentar prestar conta dos fatos observados, por exemplo, o pretérito perfeito e o imperfeito são 
utilizados para nos esclarecer os acontecimentos da aula. Podemos afirmar que os pretéritos aproximam o momento de referência ao momento do acontecimento, pois ele é utilizado para afirmar um fato ocorrido e terminado em um determinado tempo passado. Podemos ver isso, por exemplo, no uso dos verbos explanou, pediu, explicava, retornou fazendo e encerrando. Como indicado em negrito no dado acima nota-se que não há problemas em relação a esses trechos, mas as passagens contêm uma descrição que consideramos imprecisa.

No último período o autor do excerto afirma que o professor retornou fazendo a chamada; vemos que nesse caso o uso do verbo retornar no pretérito perfeito seguido por outro verbo no gerúndio nos remete a uma ideia de simultaneidade, portanto, temos o presente do indicativo no verbo fazendo, que é determinado pelo presente do indicativo + gerúndio (Fiorin, 1996, p. 25).

Podemos concluir que o aspecto durativo utilizado nesse período nos traz a ideia de que o professor chegou à sala de aula realizando a chamada, tudo de forma simultânea, o que nos dá uma ideia duvidosa de que isso de fato tenha ocorrido. Além disso, as informações suprimidas seriam mais bem evidenciadas se fossem transcritas por meio do discurso direto, mostrando as falas e explicando os momentos ocorridos durante a aula, além de especificar os últimos acontecimentos para termos clareza de como a aula foi encerrada.

Além dessas questões referentes à construção das referências textuais, não podemos deixar de destacar algumas questões referentes ao uso de verbos dicendi, pois neste dado também há problemas com relação a isso. Vemos que, por meio do discurso indireto, indicado em itálico sublinhado, o estagiário insere por meio de suas palavras a voz do professor, no entanto não percebemos a forma como o professor ressaltou aos alunos a importância da atividade, além de não sabermos a forma como o educador deu início à explicação, assim como outras informações acabam sendo suprimidas. Com base nessa omissão de informações notamos que o uso dos verbos dicendi, como mostrado, indica $o$ ato de locução, mas nem sempre o estagiário, em seguida ao verbo, esclarece as diferentes vozes presentes na sua observação.

Outro ponto verificável é que os relatórios, em alguns momentos, apresentam o discurso indireto ao invés do discurso direto, como já havíamos mencionado, dando voz aos professores e alunos ao utilizar as palavras do estagiário. Essa estratégia utilizada pelo narrador 
reestrutura as vozes dos sujeitos observados, portanto as diferentes vozes presentes dentro do enunciado acabam sendo distorcidas.

De acordo com Fiorin, na passagem do discurso direto para o indireto, a mudança de dois para um momento de referência pode acarretar transformações nas marcas temporais, já que elas, às vezes, precisam mudar do sistema enunciativo para o enuncivo. O momento enunciativo carrega consigo um eu, aqui e agora, dentro de um determinado tempo e espaço, e na debreagem ${ }^{8}$ enunciva há uma dobragem ou projeção tendo a modelagem transformada em o que fala e para quem se fala. Essa teoria dentro dos relatórios se estrutura da seguinte forma: aula observada $=$ momento enuncivo; aula relatada $=$ momento enuncivo.

Vejamos outro dado.

(vi) [...] estavam totalmente dispersos e não deram exemplos para o professor, o que ficou a cargo deste exemplificar com a seguinte frase: "arrudia o terreiro" e, em seguida, explicou que esta frase cabe mais a pessoas idosas. Assim, o educador foi seguindo com demais exemplos sobre variação de acordo com o sexo, escolaridade e fator sociocultural.

O uso de expressões "em seguida", "foi seguindo", presentes em (vi), assim como "logo após" e "ao final deste momento", no dado (v), são formas que o narrador do relatório usa para prestar conta do tempo e das ações que houve nesse período. Ainda assim, nem sempre esse tipo de colocação evidencia o que houve ao longo desse período de observação. $\mathrm{O}$ relator, ao realizar o uso dessas expressões, deveria saber explicar a forma como ocorreram os fatos dentro da sala de aula, para que então o leitor saiba de forma clara o que houve durante aquele tempo.

No excerto (vi) as expressões temporais que deveriam prestar conta da observação da aula não deixam registros claros do que houve em sala de aula. O que vemos é a descrição superficial do material observado, pois não há esclarecimentos que contribuam para comprovar as atividades observadas. As expressões em seguida e foi seguindo nos fazem refletir que, na utilização de indicadores temporais, os fatos sejam silenciados dentro dessas passagens, logo não conseguimos

8 "A debreagem é a operação pela qual a instância da enunciação projeta no enunciado as noções de pessoa (debreagem gramatical), de espaço (debreagem espacial) e de tempo (debreagem temporal)." (GUIMARÃES, 2013). 
perceber a quantidade de tempo passado durante esse período, nos dando a entender, de forma vaga, que a aula foi rápida.

Além disso, não podemos negar a importância do uso dos verbos dentro do excerto anterior, pois no caso acima o estagiário, por meio do discurso indireto, tenta mostrar a voz do professor, como identificado em sublinhado. Mais uma vez não há evidências claras de como foi realizada a explicação do professor sobre a frase arrudia o terreiro; há evidência de locução apenas quando o estagiário afirma que o professor teria dito que esta frase cabe mais a pessoas idosas, mas ainda assim vê-se que se trata de uma afirmação vaga e pouco específica sobre a aula observada.

Considerando que refletir sobre as várias temporalidades presentes nos relatórios fornece subsídios para ter noção dos acontecimentos articulados dentro das aulas registradas, há de se comentar que a instabilidade de afirmações contidas nos relatórios de estágio, bem como a invisibilidade de algumas informações, nos faz refletir sobre o processo de escrita do graduando em Letras, pois a maneira como o gênero acadêmico relatório de estágio é produzido, reflete muito sobre a sua formação acadêmica e como foi articulada à escrita até chegar ao produto final.

No caso específico da construção das referências textuais, o registro vago não só deixa de pôr em discussão o uso do tempo pelo professor, mas também levanta alguma dúvida sobre o uso do tempo pelo próprio estagiário. Aulas inteiras, de quarenta e cinco minutos, por vezes são relatadas em poucas linhas, sem que esse tempo tenha sido usado para coletar nenhum tipo de dado mais concreto. Considerando o caráter subjetivo do que é escrito nos relatórios, a observação nos faz pensar na parcial desvalorização das reflexões realizadas no que é escrito sobre as práticas didáticas, tendo em vista que deve haver um maior aperfeiçoamento das práticas pedagógicas.

Considerando que os produtos escritos revelam certa subjetividade dos conteúdos devido à falta de concretude sobre o que é escrito sobre uma aula, notamos que os relatórios se distanciam do que chamaríamos de relatos reflexivos, de modo que tangencia os avanços da pesquisa desenvolvida nas práticas de estágio. As construções das informações nos relatórios fomentam um debate sobre o papel do professor em formação, uma vez que há certa perda na autonomia sobre o que é escrito sobre uma aula, assim o "fazer pedagógico" é dado às restrições pelo próprio discente, afinal a falta de informações acorrenta o estagiário a 
um processo de incertezas sobre sua formação devido a insuficiência de informações do que ele escreve durante as práticas didáticas.

\section{Conclusões}

O presente artigo consistiu, de forma geral, em reflexões sobre como se dá o construto teórico dos estagiários por meio da escrita. Com base nisso, a pesquisa nos leva a concluir que nos relatórios de estágio ocorre, frequentemente, o apagamento de informações fundamentais sobre como se desenvolve a disciplina de estágio supervisionado. Dentre os aspectos suprimidos durante a escrita do estagiário, vemos que ocorre a manipulação de vozes ou, em alguns casos, o apagamento deles. Com base nisso vale destacar que faz parte da atividade acadêmica realizar uma boa descrição das aulas, aplicando de forma evidente os diálogos dos professores a alunos observados durante a disciplina de estágio obrigatório.

Ao final do processo de análise, compreendemos como um "bom" estagiário aquele que sabe refletir sobre o que escreve, sabendo direcionar por meio da escrita informações fundamentais sobre o que ocorre durante uma aula. Para tanto, há necessidade de que o estagiário abandone seu estágio de expectador das aulas ministradas ou produzidas para então entrar em estado crítico perante as questões levantadas durante a descrição das aulas.

Estes resultados revelam a necessidade de uma orientação mais abrangente das práticas de estágio, uma vez que as práticas de ensino durante a formação acadêmica não dependem unicamente do próprio estagiário, como também de uma relação de cooperação entre professores e os próprios discentes que necessitam compreender que as práticas de estágio supervisionado, práticas estas que não devem, jamais, serem vistas divorciadas da pesquisa, afinal compreender as diferentes práticas didáticas durante a formação é compreender o sistema no qual o discente entrará em confronto durante sua vida docente.

Refletindo sobre o aperfeiçoamento das práticas pedagógicas durante as disciplinas de estágio nos cursos de Licenciatura, havemos de defender que deva haver maior atenção às reflexões desenvolvidas durante as práticas de estágio supervisionado. Para analisar este trabalho, algumas questões devem ser necessariamente focalizadas, dentre elas, um melhor aperfeiçoamento do que é escrito sobre as práticas 
vivenciadas no estágio. Para tanto é necessária uma suficiente investigação do que é praticado durante as práticas pedagógicas.

$\mathrm{O}$ estudo funcionalista das formas de relatar as práticas docentes revela o quanto deve ser aprimorado às práticas de descrição das aulas, uma vez que ocorre a obscuridade de informações quando o estagiário descreve as práticas de estágio, para tanto, consideramos que o relatório revela uma má orientação metodológica sobre o que é produzido, logo os resultados não se delimitam apenas aos aspectos textuais do que o estagiário produz, pois há, também, reflexão sobre o papel do professor em formação.

Em nossa investigação havemos de indicar que os relatórios de estágio devem funcionar como documentos explicitadores das ações que foram desenvolvidas em sala de aula, definindo com clareza e sem obscuridade os fatos, ações, e acontecimentos inscritos durante a investigação. Indicamos que as práticas pedagógicas jamais devem ser divorciadas da pesquisa, afinal elas são tidas como a pesquisa e extensão universitária, pois fazem com que os alunos se confrontem com o sistema escolar, dando oportunidade aos mesmos de confrontar a prática aos ensinamentos adquiridos durante toda a sua formação acadêmica.

Um procedimento de análise criteriosa se baseia em boas descrições dos objetivos específicos realizados durante as práticas didáticas, bem como as justificativas, formulações de aulas e, principalmente, os procedimentos realizados e os problemas identificados durante as práticas didáticas. Esses pontos relevantes levados à escrita devem concentrar elementos formais funcionando como um projeto de pesquisa acadêmico, para que o estagiário, no momento de construir seu relato perante os fatos identificados em sala de aula, revele-os de maneira acadêmica, pondo teorias sobre o que está sendo dito, bem como observações e sugestões sobre o ensino.

Nesse contexto, a educação é posta em xeque, uma vez que os professores em formação revelam o estado da educação superior enquanto processo, de modo que o professor se mostra no momento em que realizamos os procedimentos de análise. Para lucilarmos o papel docente, tomamos como princípio o conceito de docente segundo Durkheim (1967).

Não é de fora que o mestre recebe a autoridade: é de si mesmo. Ela não pode provir senão de fé interior. É preciso que ele creia 
não em si, sem duvida, não nas qualidades superiores de sua inteligência ou de seu coração, mas na sua missão (Durkheim, 1967, p. 55).

Pairando sobre o papel do professor, haveríamos de pensar, segundo os conceitos do filósofo, que o mestre possui autoridade sobre si mesmo podendo suprir as qualidades que estão além da sua inteligência. Em vista disso, induzir os estagiários de acordo com os interesses instituídos durante as práticas de estágio é necessário, para que eles possam se adequar as situações inerentes das práticas pedagógicas durante as práticas didáticas em licenciaturas.

1. O fazer educacional como instrumento que contribua para a sua formação, cujo direcionamento esteja intimamente ligado à pesquisa.

2. Estagiário que busque adequar um trabalho produtivo aliado a compreensão ativa das suas atividades.

3. Práticas de estágio que sejam capazes de mostrar o direcionamento teórico e formativo e que sejam revelados na escrita.

\section{Referências}

Durkheim, E. (1967). Educação e sociologia. São Paulo: Edições melhoramentos.

Fiorin, J. L. (1996). As astúcias da enunciação. São Paulo: Ática.

Guimarães; E. (2013). Estudos linguísticos aplicados ao ensino. São Paulo: Mackenzie.

Maingueneau, D. (1989). Novas tendências em análise do discurso. São Paulo: Editora UNICAMP.

Rodrigues, T. (2000). Funções linguísticas do verbo dicendi. Rio de Janeiro. Dissertação (Mestrado em Letras) - Departamento de Tecnologias e Linguagens, Universidade Federal Fluminense.

Suassuna, A. (1998). Auto da Compadecida. Rio de Janeiro: AGIR. 